\title{
Una aproximación desde la Escuela Austriaca a la RSE (responsabilidad social empresarial)*
}

\author{
Fernando Chavarro Miranda** \\ Ángel Alberto Montoya Correales ${ }^{* * *}$
}

Fecha de recibido: 5 de mayo de 2019 Fecha de aprobado: 31 de octubre de 2019 Para citar este artículo: Chavarro Miranda, F., \& Montoya Correales, A. A. (2020).
Una Aproximación desde la Escuela Austriaca a la RSE. Revista Universidad E Empresa,
22(39), 1-24. https://doi.org/10.12804/revistas.urosario.edu.co/empresa/a.7885

\section{Resumen}

Por cambios ocurridos en el entorno de las organizaciones, como la globalización de los mercados, el aumento de la repercusión social, la contribución al desarrollo de las comunidades en las que participan las empresas por medio de prácticas y acciones que permiten el enriquecimiento económico, el bienestar social y la protección y promoción del medioambiente, estas se han visto en la necesidad de incorporar nuevas prácticas de RSE. Desde luego, para lograrlo se deben identificar las diferencias conceptuales de la RSE entre las teorías convencionales y la escuela de pensamiento austriaca. En este documento se consideran algunas acepciones teóricas de la praxeología, la RSE y la acción humana para determinar una aproximación a la interpretación de la RSE desde la praxeología.

Palabras clave: praxeología; responsabilidad social empresarial; Escuela Austriaca.

* Artículo de investigación, correspondiente a la línea de investigación gestión de las organizaciones

* PhD. en Administración Estratégica, Pontificia Universidad Católica de Perú. Magíster en Economía, Universidad de Los Andes. Especialista en Investigación, Universidad Santo Tomás. Especialista en Finanzas, Universidad del Rosario. Economista, Universidad de La Salle. Asesor de la Escuela de Inteligencia y Contrainteligencia, Brigadier General Ricardo Charry Solano, Colombia; Investigador Uniagustiniana. Correo electrónico: fernando.chavarro@yahoo.es; ORCID: https:// orcid.org/0000-0003-4711-7196

* Magister en Administración de Negocios, Universidad de la Salle; Especialista en gerencia financiera, administrador de Empresas, Universidad de la Salle, Colombia; Docente investigador Uniagustiniana, Colombia. Correo electrónico: Montoya_ albert@yahoo.com 


\title{
An Approach from the Austrian School to CSR (Corporate Social Responsibility)
}

\begin{abstract}
Due to the changes occurred in the environment of organizations, such as the globalization of markets, the increase in social impact, the contribution to the development of communities, in which companies participate through practices and actions that allow economic enrichment, social welfare, and the protection and promotion of the environment, these have seen the need to incorporate new cSR practices. To achieve this, the conceptual differences on CSR between conventional theories and the thinking of the Austrian school of thought must be identified. This document considered some theoretical meanings of praxeology, corporate responsibility, CSR, and human action, in order to determine an approach for interpreting csR from praxeology.
\end{abstract}

Keywords: Praxeology; corporate social responsibility; Austrian school.

\section{Uma Aproximação desde a Escola Austríaca à RSE (responsabilidade social empresarial)}

\section{Resumo}

Por mudanças ocorridas no entorno das organizações, como a globalização dos mercados, o aumento da repercussão social, a contribuição ao desenvolvimento das comunidades, nas que participam as empresas por meio de práticas e ações que permitem o enriquecimento econômico, o bem-estar social, a proteção e promoção do meio ambiente, estas se têm visto na necessidade de incorporar novas práticas de RSE; e certamente para consegui-lo, devem-se identificar as diferenças conceituais sobre a RSE entre as teorias convencionais e o pensamento da escola de pensamento Austríaca; é por isto que neste documento se considera ter presente algumas acepções teóricas da praxeologia, a responsabilidade empresarial, RSE e a ação humana, para chegar a determinar uma aproximação à interpretação da RSE desde a praxeologia.

Palavras-chave: praxeologia; responsabilidade social empresarial; escola austríaca.

\section{Introducción}

El denominado debate del siglo xx en el ámbito de la economía, que tuvo consecuencias políticas, sociales y culturales, se centró en dos posiciones que se contraponen: el keynesianismo y la Escuela Austriaca. Las dos lógicas con sus posturas, pero sobre todo con su visión del hombre, entrevén una lógica de actuación que da pie y sentido no solo a las corrientes económicas contemporáneas, sino a la forma en que los actores del mercado se ven a sí mismos, actúan e interactúan y por ende son sujetos que se suscriben a lineamientos éticos y morales.

El ámbito keynesiano permite entender las raíces y la concepción que se tiene del hombre, que se conecta con la lógica clásica definida por Adam Smith en 1764, en la que se menciona 
al denominado bomo-economicus, aquel ser que tiene como parámetro y principio la búsqueda de su bienestar, así que es egoísta por naturaleza dado que solo se enfoca en su ser, el bienestar o las metas de otros son irrelevantes para su actuar. Lo anterior se ejemplifica en el ámbito de la administración de empresas al tomar como parámetro la denominada administración científica de Taylor (1911), quien entendía, bajo el precepto de Smith, que el hombre al buscar solo su interés en una relación laboral solo estaría motivado por el salario, así un trabajador será más productivo si recibe un mayor salario, es esa la relación causa-efecto del mercado laboral que conecta el modus operandi de personas, trabajadores y empresas.

En este punto, se llega a la premisa inicial de la economía clásica: el hombre es egoísta, el aporte de Keynes a esta consideración tiene que ver con la forma en que se administran todos los recursos en la economía, tanto públicos como privados. De allí su sentencia que considera al libre mercado como algo peligroso, puesto que no se sabe si al hombre que toma decisiones de forma adecuada, se le podría denominar un ignorante, quien al no tener limites sobre su acción en el mercado, asociados a elementos como el crédito y su relación con el consumo, podría tomar malas decisiones, que de forma masiva condicionan elementos como la inflación. Precisamente la respuesta de Keynes ante este grado de ignorancia, se basa en la función del Estado, donde este no solo debe regular las relaciones entre los individuos, que se vincularían a los pleitos propios del derecho comercial (se puede sumar el laboral y el privado), sino que puede y debe actuar de lleno en la economía; el Estado pasó de ser juez a ser parte, esto se materializa por medio de las políticas fiscales y monetarias.

En el ámbito monetario y con supuesta independencia del Banco Central, se generan medidas y controles relacionados con la inflación no solo en la cantidad de dinero disponible en la economía por medio de elementos como la emisión, sino de otros como el movimiento de las tasas de interés o la compra y venta de divisas. Desde el punto de vista fiscal, es lo que se denominaría gasto publico, de allí que se relacione con instrumentos tan simples como la variación de impuestos o simplemente el funcionamiento del aparato estatal, sumado al desarrollo de planes y programas (obras publicas, servicios públicos, etc.), que deberían atacar falencias o vacíos con el fin que la sociedad en su conjunto sea más competitiva. 
Aunque estas dos políticas tienen dimensiones globales o generales y acuden más a un problema macroeconómico, si se lleva al ámbito microeconómico e inclusive empresarial, se infiere el concepto de hombre asociado a aquel ser, que aunque es egoísta y busca su bienestar, es ignorante al controlar sus impulsos y recurrir al mercado, de allí que sea importante que desde la figura del Estado, independientemente del sentido democrático, se genere un orden; en este caso, el contrato social no solo es por seguridad, sino sobre todas las decisiones que toma un individuo en cuestión de maximizar sus beneficios o alcanzar sus metas.

La escuela austriaca presenta otro paradigma, el cual no solo se puede asumir de la crítica de Hayek al modelo keynesiano y sus demostraciones matemáticas; la visión inicial se puede asentar en la praxeología de Mises. Este texto se centra en determinar el concepto de praxeología asociado a la perspectiva de hombre y su connotación en el marco de la RSE como propuesta metodológica.

\section{Revisión de la literatura}

En este apartado se hace una exploración de referencia en torno a la concepción de praxeología, para finalizar en la praxeología en economía definida por Mises como acción humana; igualmente, se hace una indagación de referencia, en torno al concepto de RSE.

\subsection{Praxeología}

Tratar de definir la praxeología hace parte del juego mediante el cual, en los intercambios con los profanos, los praxeólogos se reconocen. Que alguien que se presente como praxeólogo nos dé una respuesta clara y directa a la cuestión “¿qué es eso de praxeología?”, no es un verdadero praxeólogo. Un verdadero praxeólogo sabe que la definición que él podría dar a un novato no podrá jamás ser comprendida directamente, de un solo golpe ni enteramente. Haría falta el contexto práctico-operacional, que da cuerpo y sentido a las palabras y que no se transmite sino mediante la experiencia: "Ven, practícala y comprenderás”. Las características del modo praxeológico de ver las cosas, sin el entrenamiento requerido, no podrían ser captadas. Obviamente, los praxeólogos no son los únicos 
profesionales que se encuentran en esta situación. Hecha esta distinción, intentemos aproximarnos al concepto.

La praxeología se entiende como un discurso (logos) construido después de una seria reflexión sobre una práctica (praxis) particular y significante (Juliao, 2011) como un procedimiento de objetivación de la acción, como una teoría de la acción; por el tipo de análisis que realiza y pretende hacer de que dicha praxis sea más consciente de su lenguaje, de su funcionamiento y de lo que en ella está en juego, sobre todo del proceso social en el cual el actor o practicante está implicado y del proyecto de intervención que construye para cualificar dicho proceso; todo esto con el fin de acrecentar su pertinencia y su eficacia liberadora (Juliao, 2011). Ella es el resultado de un análisis empírico y de un discurso crítico; la praxeología designa, desde el principio, una reflexión práctica sobre los principios de la acción humana y de sus técnicas, pero busca, igualmente, los principios generales y la metodología adecuada para una acción eficaz y pertinente.

Ahora bien, independientemente del uso del término praxeología propiamente dicho, la preocupación económica, lógica y organizacional que se ha querido que exprese (sobre todo en Norteamérica) corresponde al momento y se encuentra en la inmensa mayoría de las grandes corrientes que jalonaron el siglo xx: el pragmatismo norteamericano, el marxismo, la epistemología de las ciencias humanas y sociales, tanto en Moreno como en Lewin o incluso en Moles, con su teoría de los actos, o en Talcott Parsons o Bourdieu, hasta llegar al "retorno del sujeto" bajo la forma de actor en las sociologías contemporáneas (Bourdieu, 1972). Efectivamente, todas ellas se interesan por la eficacia del conocimiento y por su capacidad para mejorar la condición humana. Es lógico, entonces, preguntarse por la utilidad de la investigación. ¿Para qué sirve? ¿A quién le sirve? Por su parte, y de un modo bastante extraño, Garfinkel (1991), el fundador de la etnometodología, cuando ya no reconoce como suyas sus propias criaturas teóricas y cuando se siente traicionado, se pregunta, seriamente, si no debe rebautizar tal enfoque, de inspiración decididamente fenomenológica, para darle el nombre de neo-praxeología.

En su Esquisse d'une théorie de la pratique, Bourdieu (1972) sitúa la praxeología entre los modos de conocimiento teórico con el conocimiento fenomenológico y objetivista: 
la connaissance que l'on peut appeler praxéologique a pour objet non seulement le système des relations objectives, mais les relations dialectiques entre ces structures objectives et les dispositions structurées dans lesquelles elles s'actualisent et qui tendent à les reproduire, c'est à dire le double processus d'intériorisation de l'extériorité et d'extériorisation de l'intériorité : cette connaissance suppose une rupture avec le mode de connaissance objectiviste, c'est à dire une interrogation sur les conditions de possibilités, et par là, sur les limites du point de vue objectif et objectivant qui saisit les pratiques du dehors, comme fait accompli, au lieu d'en construire le principe générateur en se situant dans le mouvement même de leur effectuation (pp. 157-253).

Podemos considerar que actualmente existen dos corrientes (no del todo opuestas) en la comprensión de la praxeología: la europea (el concepto es praxeología), más filosófica y hermenéutica, centrada en la comprensión de la acción humana (praxis), y la hermenéutica, en tanto actividad social, como conjunto de ideas, valores, actos y palabras orientadas al progreso del otro (educación) y al cambio de su contexto con miras a un acrecentamiento del bienestar personal o social. La praxeología es una teoría de la acción y se presenta como el enfoque que otorga un lugar adecuado, en el campo de la teoría y la investigación, al profesional práctico-reflexivo, aquel que busca aprehender su propia experiencia y formalizar desde ella una teoría apropiada. La acción, la praxis, el sentido de esta y la necesidad de estrategias pertinentes son los hitos de un itinerario que conduce a la adopción de la praxeología como método de intervención y enfoque de investigación (Bourdieu, 1972). Es la que aplicamos acá. La norteamericana (el concepto acá es praxiología) es más pragmática y se centra en la búsqueda de la eficacia de la acción humana (praxis), que facilita el proceso de toma de decisiones mediante una justificación (o fundamentación) de la elección de unos determinados valores. La praxiología, en la medida en que es una decisión oficial o una opción privada, es una actividad dirigida a la solución de un problema, comprende la determinación de los fines, la descripción de las tendencias, el análisis de las condiciones, la proyección de los cambios y el descubrimiento, evaluación y selección de las alternativas. Tiene mucho que ver con la estrategia y la planeación, su campo de influencia se confunde con el de la ciencia política y las ciencias del comportamiento y, en general, con todos los procesos de adopción de decisiones. Esta intención confirma, sorpresivamente, un parentesco detectable con la comparación entre ciertos objetos de la micropsicología de Abraham Moles y otros de la microsociología de Harold Garfinkel, igualmente tomados de situaciones de la vida cotidiana (Moles \& Rohmes, 1977). 
Como lo quería Kant (1966), otro pensador de la razón práctica, la educación difícilmente puede ir separada de un deseo de progreso hacia una mayor perfección. Por eso, cuando un profesional, tratando de resolver y comprender una situación problemática, se esfuerza por observar el efecto de sus propias acciones y prácticas para mejorarlas en el momento de volverlas a realizar, se convierte en lo que Donald Schön (1998) llama un profesional reflexivo. ¿En qué consiste esta reflexión en la acción que realiza dicho profesional? En la lógica del pensamiento de Schön hay que entenderla como el proceso mental que permite a un profesional adaptarse a cada situación que se le presente en el ejercicio de su profesión; una especie de diálogo continuo entre él y los acontecimientos de su práctica profesional. Al usarla sistemáticamente, el profesional puede aumentar la eficacia de sus intervenciones, desarrollando progresivamente una especie de modelo de intervención a la medida. Schön (1998) afirma que esta reflexión es también una reflexión sobre la acción. Así, en una situación que parece difícil de controlar, sugiere que el profesional "reestructure el problema y, en esta nueva tentativa [que Schön llamará] una experiencia de estructuración, tratará de imponer su voluntad" (p. 81). Así, la forma de conocimiento que caracteriza a este profesional reflexivo es la del "conocimiento en uso"; no se trata de una reflexión después de la práctica, sino de una reflexión durante ella. La reflexión es una parte integral de la práctica, y ello hace que el profesional tenga que ser siempre crítico (Schön, 1998).

Yves St-Arnaud y Alexandre L'Hotellier, investigadores canadienses, afinaron esta teoría de Schön y la llamaron praxéologie, en tanto que pretende transformar la investigación asociando el saber (logos) y la acción (praxis). Ellos la definen así: "La praxeología es un proceso investigativo construido, de autonomización y de concientización del actuar (en todos los niveles de interacción social) en su historia, en sus prácticas cotidianas, en sus procesos de cambio y en sus consecuencias" (St-Arnaud, 1992, p. 95), es decir, una lógica uniforme y constante de la acción y del aprendizaje humanos. La praxeología proporciona instrumentos prácticos para determinar si la acción que se realiza es eficaz y cuáles serían las otras acciones de mejora a emprender. Ambos autores sostienen que la acción, más que ser simplemente la aplicación de un conocimiento, puede ser la fuente misma de ese conocimiento. Además, como el procedimiento praxeológico intenta reducir las fronteras (dualistas o de otro tipo), puede servir en donde se lo desee aplicar. El diálogo entre el saber y la acción puede llevarse prácticamente a todas las situaciones. 
Con base en todo lo anterior, se puede decir que el quehacer praxeológico cumple una cuádruple función: de conservación, enriquecimiento, gestión y apropiación de los saberes que produce la práctica, función similar a la de los knowledge managers (gerentes del conocimiento). A diferencia del profesional práctico, el profesional reflexivo o praxeólogo se interesa más por las prácticas eficaces, por el saber-hacer que implican, que por los resultados de estas (los hechos, objetos, artefactos, etc.). A diferencia del práctico, comprometido con la complejidad de lo real, el praxeólogo tiene que realizar un ejercicio de abstracción, de pensar por separado aquello que no está separado: se trata de descomponer la práctica y sus procedimientos en tantas fases como sea necesario para comprenderla y, enseguida, conducirla o reconducirla con pleno conocimiento y, de ser posible, modelizarla. Este desplazamiento de lo concreto vivido o percibido (la práctica o la observación de la práctica) a lo concreto pensado, para retornar a lo concreto construido, y de ahí a lo concreto aprehendido, es el quehacer fundamental de la praxeología (Juliao, 2002). Es una revalorización de la práctica que, como lo dijo Bourdieu (2003a) "siempre está subvalorada y poco analizada, cuando en realidad, para comprenderla, es preciso poner mucha más competencia técnica, mucha más, paradójicamente, que para comprender una teoría" (p. 75).

La lógica de la acción (praxis) se articula con la del conocimiento (logos); la clásica oposición entre teórico y práctico se transforma en una complementariedad dialéctica entre saberes y saberes de la acción, que favorece un movimiento en espiral entre lo vivido, la práctica y el pensamiento, que termina haciendo de esa práctica una praxis.

La praxeología parte de la idea de que desde la praxis y la práctica - la distinción entre los dos conceptos se concretará más adelante- se pueden construir saberes, se puede extraer la estructura de una experiencia considerada interesante y pertinente en función de cierto número de objetivos que en ella se dan, o de un cierto número de resultados esperados; de ella se puede extraer lo esencial y eso puede ser transferido en un proceso netamente educativo. Eso esencial es la racionalidad interna de la praxis, sea que haya sido bien controlada por los actores mismos o que haya sido empírica y espontánea.

En el campo educativo es justamente este anclaje antropológico, cultural y, por tanto, histórico el que implica cosmovisiones y valores, lo que constituye el origen y la fuerza de una praxis no totalmente dependiente de una poïesis autónoma. Conviene, entonces, 
reconocer y reivindicar este enraizamiento, en vez de pretender sustituirlo por modelos técnicos, racionales y abstractos. El saber-hacer poïético y económico, propio de una producción instrumental y técnica de la operacionalización de una fuerza de trabajo, cede el puesto aquí del saber-ser sí mismo (realización más que producción) a la noción de un trabajo sobre sí mismo, a la primera persona del singular o del plural (yo o nosotros), en el sentido en que Sartre (1960) en la Critique de la raison dialectique decía que el hombre se construye permanentemente a través de lo que hace; es decir, que se trabaja a sí mismo trabajando. El sujeto pasará así, más o menos, a convertirse en autor. Y es esta capacidad de autorización, en tanto que creación progresiva y continua de sí, social y personal, constituida tanto de intencionalidades conscientes como de elaboraciones inconscientes, lo que nos parece lo más representativo de una praxis educativa, en tanto que esta para ser creativa se distingue efectivamente del conformismo, de la tendencia a la reproducción, que caracteriza las prácticas sociales artificiales a fuerza de no buscar sino profesionales, estrategas y técnicos (Sartre, 1960).

Lo planteado anteriormente permite asumir que ser sujeto (en este caso sujeto-objeto de investigación) es ser proceso, síntesis de aquello que Deleuze (2002) llamó sus principios constitutivos: la creencia y la creación. Es moverse entre lo dado (lo instituido) y lo creado (lo instituyente), es hacerse sujeto en la medida en que se supera (trascendencia), reflexiona y se reflexiona a sí mismo en sus prácticas; es creencia porque infiere lo que la naturaleza y la cultura le dan, pero es también creación en tanto que inventa y construye. Todo ello solo es posible desde la propia subjetividad (Castoriadis, 2004). Ser sujeto es estar en esa tensión permanente entre lo dado y lo creado y en la implicación subjetiva de eso que se quiere expresar o entender. Para la investigación eso quiere decir que solo involucrándome en lo investigado podré ir perdiendo el estado de individuo-observadorpasivo para ser sujeto-constructor-activo. Lógicamente, ser sujeto, al menos en la investigación praxeológica, me lleva a percibir de modo diferente lo epistemológico: como investigador-praxeólogo y actor social me hallo en relación constante con lo investigado (mi propia práctica); por tanto, desconfió de todo aquello en lo que no me encuentro inmerso. Y así paso de una epistemología como teoría del conocimiento científico a una praxis epistemológica critico-comprensiva de mi ser y mi hacer (mi práctica) en la construcción del conocimiento. Eso significa, como afirma Jaramillo (2003), que tendré la capacidad de tener conciencia histórica y reflexiva de una realidad que observo y me observa, rodeo y me rodea, absorbo 
y me absorbe; que usaré una epistemología dinámica e impalpable; que seré un investigador reflexivo, curioso y crítico pertinaz, que se siente con el derecho de expresar su interioridad.

Antes de avanzar más en esta línea, es necesario concretar la distinción que aquí se hace entre práctica y praxis. Como se muestra en el siguiente ejemplo. Cada mañana, cuando me despierto, preparo un café sin que ello me exija una real actividad intelectual; tengo necesidad del café para despertarme plenamente y si hacerlo implicara un trabajo intelectual y práctico complejo, nunca lograría preparar mi café por tanto no me despertaría realmente. Prepararlo es de esos actos automáticos y programados, lo que me permite dejar volar mi imaginación y mi atención hacia otras cosas: cómo amaneció el día, el trabajo que tengo por delante, mi último sueño. Preparar el café es ciertamente una práctica, una que se ha vuelto espontánea y de algún modo incorporada en mi cotidianidad, lo que no significa que, en ocasiones, no pueda fracasar - por ejemplo, puedo estar atrasado y no alcanzar a prepararlo o puedo no encontrar con qué prepararlo- (Juliao, 2011). Esto es lo que Bourdieu (1972) llama un habitus ampliamente determinado por la educación y la cultura. Ahora bien, la mayor parte de nuestras actividades cotidianas son de este tipo: prácticas espontáneas, adquiridas e interiorizadas, donde la actividad intelectual es casi nula (Bourdieu, 1972).

Imaginemos ahora que soy un hotelero profesional, preocupado por el bienestar de mis clientes y por su fidelidad a mi negocio. Yo voy, entonces, a preocuparme de modo especial por la preparación del café y de las demás bebidas del gusto de los clientes. Tendré que utilizar mi inteligencia práctica, adaptar pertinentemente mis medios a los fines deseados, realizar mejoras y rectificaciones, desconfiar de mis automatismos, probablemente adquirir nuevos conocimientos, investigar al respecto, etc. (Juliao, 2011). Este otro modo de preparar el café es de otra naturaleza: se trata de una praxis muy diferente de la práctica espontánea, que requiere de otra postura, implica una reflexión intelectual y pone en juego métodos, procedimientos y tácticas regularmente repensados en el contexto de una profesión concreta.

La praxis es entonces una práctica sensata, no espontánea sino pensada, que supone un procedimiento intelectual y no una simple repetición mecánica. Obviamente, no todas las prácticas cotidianas tienen que ser convertidas en praxis, de ser así la vida sería imposible (Juliao, 2011). 
Praxeología y praxis están íntimamente ligadas aunque no obedezcan a las mismas lógicas. La praxis es la ejecución de técnicas en coherencia con finalidades (lógica tecnológica); la praxeología es la construcción de saberes de la acción (lógica científica). El objeto principal de la praxeología es la elaboración, experimentación y validación de modelos de acción que sean útiles para la gestión de la praxis; permite formalizar, validar y programar lo que generalmente se hace de modo espontáneo, intuitivo y empírico.

\subsection{Responsabilidad social}

Según López, Ojeda y Ríos (2011), desde el enfoque empresarial, los acontecimientos de los últimos tiempos han provocado que la sociedad perciba la empresa no solo desde una perspectiva financiera. Los cambios ocurridos en el entorno, la mayor globalización de los mercados, el aumento de la repercusión social, la contribución al desarrollo de las comunidades en las que se participa por medio de prácticas y acciones que permiten el enriquecimiento económico, el bienestar social, la protección y promoción del medioambiente y la necesidad de incorporar prácticas de buen gobierno y realizar inversiones socialmente responsables han llevado a las organizaciones empresariales a reorientar sus sistemas de gestión, mostrando una mayor preocupación por la implementación de prácticas socialmente responsables (Kanji \& Chopra, 2010).

Por otro lado, Calderón, Álvarez y Naranjovalencia (2011) consideran que la gestión humana está trascendiendo su papel instrumental para convertirse en apoyo para la competitividad de las organizaciones, uno de los aspectos en que tiene que apoyarlas es en el cumplimiento de su responsabilidad social. Igualmente, para Peláez (2011), la rse y la gestión humana son dos enfoques que generan un aporte estratégico para las empresas. Sin embargo, en Colombia se han evidenciado dificultades para comprender su relación, entre ellas se destacan la escasez de tiempo, la generación de costos de las actividades de RSE, la no generación de valor de la RSE, la falta de incentivos para su implementación, la falta de presión de parte de los acreedores y accionistas, el hecho que la cultura organizacional va en contravía de los objetivos de la RSE y de la integración estratégica de la empresa, la visión cortoplacista de la empresa no satisface la planeación estratégica de la RSE, que es a largo plazo, y el éxito de la RSE depende del tamaño y la competitividad de las empresas (Herrera et al., 2014). 
Por lo anterior, Porter y Kramer (2002) opinan que actualmente la RSE es considerada como un enfoque de gestión estratégico, generador de oportunidades, innovación y ventaja competitiva con repercusión en la imagen y reputación de las empresas. Alvarado, Bigné y Currás (2011) consideran que ha existido una evolución que está dando lugar a que nuevas aproximaciones al estudio de la RSE se despeguen de racionalidades tradicionales, abogando por una concepción de la empresa en la sociedad más holística e integradora, y proyectando una noción de esta como algo más que un buen instrumento para hacer negocios.

Saldarriaga (2013) aborda la responsabilidad social y la gestión del conocimiento como estrategias de gestión humana conexas e inseparables en las organizaciones. Estas estrategias hacen posible que la organización mire hacia sí misma y reconozca los impactos que estas prácticas tienen sobre sus miembros, asumiéndolas no solo como actividades que le generan ganancias económicas y visibilidad en el escenario social, sino como parte integral de su forma de concebir y administrar su talento humano.

Por otra parte, Guibert (2009) considera, cuatro décadas después de 1970, frente a las polémicas opiniones de Friedman sobre la responsabilidad social corporativa (RSC), que aun en contextos anglosajones se enfatiza el papel determinante de la propiedad del capital. Por tanto, es así como se extiende rápidamente una nueva forma de percibir la actividad empresarial, resultado de las rápidas transformaciones que vienen experimentando las sociedades avanzadas (desarrollo económico y social). Por eso los acreedores y accionistas del siglo xxi son más sofisticados e informados que los de la década de los 70 del siglo xx. Así, en la actualidad, parece imponerse en la gestión empresarial un enfoque comprometido con el cuidado del impacto económico, social y medioambiental de las decisiones y actividades de la empresa.

A diferencia de García y García (2005), Perdiguero (2005) cree que la RSE ha evolucionado y variado en función de los valores sociales imperantes, de ahí que lo voluntario y lo obligatorio también lo hagan, al igual que los valores sociales. Por tanto, estos valores son voluntarios con respecto a lo medioambiental, a la no discriminación en el trabajo por razón de sexo o seguridad laboral, dada la magnitud de las empresas y la despersonalización de su responsabilidad, y es así, que esta depende de los objetivos de la acción empresarial. 
De otro lado De Sebantián (2007) sostiene que la empresa, entendida como ente relacional, ha quedado tradicionalmente apartada de los circuitos académicos porque no permite explicar la actuación de las pymes en la función del conjunto de redes sociales sobre las cuales se apoya y la noción de capital social ni comprender la razón detrás de las actuaciones que desbordan la actividad estrictamente mercantil de la empresa, basadas en elementos exógenos tales como los valores del empresario, la mejora del clima laboral, la innovación y la presión ejercida por la sociedad y el gobierno.

Para Caneda (2004) siempre ha existido una conexión inevitable entre las concepciones morales y las actuaciones económicas, tal como lo indicó Adam Smith en su obra Teoría de los sentimientos morales, en la que considera la inseparable relación entre la vida económica y la vida social. De ahí los elementos necesarios que deben cumplir en la RSE las organizaciones en sus relaciones internas y externas. Igualmente es indispensable el acercamiento a la RSE mediante la integración voluntaria por parte de las empresas en sus preocupaciones sociales y morales para sus operaciones y las relaciones con sus acreedores y accionistas.

Escudero y García (2014), en su estudio en América Latina, encontraron que para el futuro avance en la RSE latinoamericana es conveniente integrarla a la sostenibilidad e innovación lo cual permite a las empresas asumir los retos medioambientales y sociales, para ello es preciso examinar los factores de compromiso con la sostenibilidad; las estrategias que se aplicarán en la RSE de acuerdo al plan estratégico de la empresa; la estructura, la transversalidad de la alta gerencia y el impacto de la sostenibilidad, y la innovación. Las prácticas actuales de sostenibilidad sobre la RSE y la creación de valor en América Latina se examinaron en cuatro países específicos: México, Brasil, Argentina y Chile, donde se observaron aspectos de interés como sus características económicas con un énfasis en la situación del sector de generación y distribución de energía, la situación actual de la RSE en los mismos y la relación entre esta y la innovación.

\subsection{Mises: Acción humana}

En su obra, Acción humana, Mises (1949) se centra en generar unas bases de carácter praxeológico para explicar la forma en que interactúan los actores en el mercado y, a partir de esto, establecer la importancia del libre mercado a la hora de generar bienestar para la población. En primera instancia, el autor define la praxeología desde dos consignas: lógica 
de la acción humana e interacción o marco de comprensión de la conducta humana intencional. Al analizar la primera consigna se evidencia la palabra lógica que puede ser asumida desde dos posiciones como un componente racional, es decir, que se le da atributo desde la condición humana, en tanto que por asociación y familiaridad, se puede entender como sentido común, que se asocia a las acciones que desarrolla el hombre, generando un sentido de praxis, sumado al concepto de interacción que acude a entender al ser humano como un ser social. La segunda consigna habla de comprender la conducta de las personas como un marco de la construcción de principios básicos o generales de carácter irrefutable, propio de acciones que se tipifican como intencionales, lo que posibilita el cumplimiento de la condición racional.

De allí que Mises asuma el razonamiento discursivo como la metodología para aplicar la praxeología en el ámbito económico, haciendo alusión a que todo el constructo teórico y el marco de comprensión se sostienen bajo el desarrollo de supuestos, entendidos como la deducción lógica de hechos indiscutibles como: "el agua moja".

Es así, que el hombre es entendido como alguien que, por su capacidad racional, traza en diferentes espacios de tiempo metas y objetivos. En ese sentido, se es aspiracional, el humano tiene visión, crea y reproduce el mundo; logra adaptar valores para establecer sus metas por medio de líneas de comportamiento. De allí que exista una asociación individual y no societal para entender los valores, metas y acciones, debido a que las múltiples combinaciones hacen que no se pueda cuantificar ni encasillar en una sola lógica de comportamiento a las personas.

Ahora bien, la aclaración es pertinente debido a que las razones de comportamiento o los factores que impulsan la acción no son cuantificables. Es del campo de la psicología entender los elementos conscientes y subconscientes, en tanto que la praxeología estudia la acción, entendida como la definición de preferencias — son elecciones que determinan intentos para llegar a un fin en particular-.

El primer marco de referencia que genera Mises (1949) se centra en establecer condiciones para que un hecho se pueda tipificar o categorizar como una acción deliberada o intencional. Para esto, se plantean tres condiciones: (1) malestar, (2) imaginario y (3) fe en la acción. 
El malestar se asume como una necesidad o una situación que perturba o genera incomodidades para el hombre, un ejemplo de ello es la pirámide de necesidades de Maslow (1943), donde existen elementos básicos como el hambre, el frío, la sed, así como el aislamiento social o la falta de reconocimiento, que se convierten en malestares con diferentes grados de perturbación o categorización a partir de las condiciones de vida actuales del individuo. El imaginario es una proyección a futuro, la visión donde la persona se imagina en un estado sin ese malestar — si usted tiene un malestar como el hambre, se proyecta en un estado sin ese malestar, no se representa imaginando la comida ni comiendo, sino con la sensación de estar saciado o satisfecho- Finalmente, la fe en la acción se entiende como el punto o momento en que el individuo establece una preferencia, toma una decisión pensando o creyendo que es la mejor, la más efectiva para superar el estado de malestar o alcanzar el imaginario; en ese sentido, al analizar una serie de posibilidades, el individuo selecciona y escoge un camino; después de cumplir estas tres etapas se tiene como resultado la acción como tal.

Debido a que estas condiciones son irrefutables por su sensor lógico, en otras palabras, en su haber metodológico, se expone que si no existe malestar, no habrá acción, puesto que la persona no estaría motivada a cambiar de estado, sería una persona feliz. Por otro lado, si no proyectara el imaginario y depositara fé en la acción, sería una persona condenada al destino, que tiene una serie de malestares, pero no logra generar un proceso de toma de decisiones que lo lleve a actuar. Al final, la suma de las tres condiciones posibilita que la acción se interprete como principio para alcanzar la felicidad, de allí que se siga cumpliendo el parámetro de no cuantificación de las personas y el reconocimiento de su individualidad y en ese sentido de su libertad frente al grupo social.

En ese sentido, toda acción deliberada se considera racional, pues se genera a raíz de un proceso lógico de racionamiento a partir de las tres condiciones, que responden a preferencias estrictamente subjetivas, de allí que no se puedan plantear juicios de valor sobre las acciones de los otros; es una conciencia sobre la libertad de elección, decisión y acción, que reconoce la diferencia en las preferencias del otro.

Una vez se identifican estas condiciones, se establecen elementos que se podrían denominar categorías o variables, que ayudan a perfilar el actuar de las personas. En primera instancia la concepción del tiempo, entendiendo que las acciones solo se dan en el presente, debido a que el malestar es algo que se vive, de allí que dependiendo del malestar se puedan dar acciones de forma inmediata, que parecen ser instintivas, pero que acogen 
el mismo sentido racional potenciado por la experiencia. En ese sentido, una acción sigue a la otra, las elecciones propias de la acción siguen un orden sujeto a preferencias, si el individuo tiene hambre, puede acudir a la elección bajo una restricción presupuestal de ciertos productos y simplemente les da prioridad para generar un curso inicial de acción, valoración que es subjetiva y que atiende al concepto de utilidad de los bienes, ya sea de uso o de valor, siendo la primera la utilidad expresada sobre la función que persigue el bien o servicio, un para qué fue creado, frente a la de valor entendida como los usos y atributos diferentes que le puede dar la persona a un bien más allá de su función inicial.

Una segunda variable que se encadena con el tiempo es la incertidumbre, debido al trasegar continuo entre pasado, presente y futuro, no solo porque una acción deba seguir a la otra, sino por la condición propia de escasez del tiempo como recurso. Esto implica los hechos impredecibles que no dependen de la conducta intencional del individuo como los cambios naturales y las opciones humanas. De allí que existan formas para actuar frente a la incertidumbre como el juego, entendido como dejar acciones a la suerte u ocurrencia, la especulación haciendo alusión a que un alto grado de información reduce el riesgo de las decisiones y la ingeniería, entendida como la planificación y control alrededor de los recursos. Estos se consideran abordajes, pero no generan una confiabilidad total, de allí que la suerte se pueda ver empañada, no se pueda tener el dominio de toda la información y de las fronteras de conocimiento con respecto a un tema o en su momento no se puedan controlar todas las variables, en especial el conocimiento de las personas, para ejecutar un plan; por ello en praxeología existe la predicción estrictamente subjetiva, cualitativa.

Partiendo de que el tiempo es un recurso escaso por excelencia, Mises plantea retomar el concepto de capital, entendido como acumulación de tiempo. De esto se desprende la concepción de la formación de capital como un ahorro de tiempo; así los bienes de capital son aquellos que acumulan tiempo. Al relacionar tal dimensión con el mercado, se habla inicialmente de intercambio o trueque, que establece la voluntad de las personas de cooperar -intercambio voluntario- con el fin de que las personas alcancen tales metas subjetivas. A partir des esta concepción se habla del mercado como un instrumento de paz, gracias a que en este coinciden múltiples actores con diferentes malestares, que al sumarse a la lógica del mercado pueden superar mayores cantidades de necesidades, que si actuaran individualmente, el mercado da múltiples opciones. 
Ahora bien, el problema que trae el intercambio es precisamente la coincidencia de deseos en un mismo lugar y espacio para efectuar el trueque, además de la invisibilidad que plantean ciertos bienes, en especial los servicios. Por esto surge la moneda, entiéndanse los precios como las relaciones de intercambio entre los bienes y el dinero como transmisor de información general sobre estos.

En ese ámbito, Mises conecta la catalaxía con el ejercicio de definición de precios e intercambio en el mercado, generando una nueva postura que se diferencia del pensamiento clásico, que retoma Keynes, donde el individuo como actor del mercado no solo busca maximizar la ganancia sobre los precios de los bienes — negociación de suma cero-, sino sobre la definición de programas de intercambio que se definen sobre elementos subjetivos como las doctrinas y prejuicios - paradigmas-.

\section{RSE: interpretación praxeológica}

En este apartado se busca conectar e identificar puntos comunes tanto a nivel epistemológico como práctico desde la Escuela Austriaca por medio de la praxeología de cómo se articula la concepción de RSE.

Analizando los postulados desde el ámbito de la praxeología y la visión económica de Mises, la primera conexión se presenta al entender que tanto individuos como empresas son actores racionales, en ese sentido generan conductas intencionales en pro de satisfacer alguna necesidad. Por lo tanto, toda decisión que sea objeto a nivel administrativo, jurídico, legislativo, de consumo o de producción parte de un hecho irrefutable: somos consientes y en ese sentido responsables de nuestras acciones, dado que generamos un proceso lógico que consiste en la identificación de un malestar por parte del actor, la imaginación asociada a la proyección sin el malestar y la fe de que esa acción va a generar un cambio del estado inicial. 
Se podría establecer un debate sobre la percepción de los malestares e inclusive la forma en que los actores construyen imaginarios, pero sería un tema asociado a la comprensión de la acción y no de su simple interpretación. Bajo esta premisa se asume como espacio de comprensión e interés la última etapa, fe en la acción, en el supuesto de que las personas podrán elegir diferentes caminos para solucionar un malestar en específico, ya sea individual o social; el voto es un ejemplo de esto a nivel democrático.

Ahora bien, el asunto es que esa elección puede contribuir a la superación del malestar; sin embargo, tal como lo refiere Pigou (1920), las externalidades se entienden en un mercado de competencia perfecta como los efectos o consecuencias que puede tener la producción, venta o consumo de un determinado producto o servicio; así es como estos efectos pueden llegar a ser positivos o negativos.

A nivel praxeológico se asume la fe como una acción determinada que debe contener o relacionar los costos o beneficios que esta puede generar en el entorno del individuo, lo cual es una medida espacial que incluye la relación con el ambiente, así como con los seres humanos y por supuesto la relación con el Estado. Esto lo evidencia el modelo Innova RSE, donde esta se enfoca en tres ámbitos clásicos: económico, ambiental y social. Desde el punto de vista económico, se caracteriza a la empresa socialmente responsable como aquella que cumple con los requisitos legales de funcionamiento y cumplimiento de normas y disposiciones comerciales, donde se tienen en cuenta las prácticas financieras. Desde el punto de vista ambiental, se enfoca en cumplir las normas ambientales estipuladas no solo en el desarrollo de sus procesos productivos, sino en la cadena de valor, insumos y productos. El último componente tiene que ver con la forma en que la empresa se relaciona con sus diferentes acreedores y accionistas, los cuales pueden ser internos o externos. Los primeros son aquellos que participan en la estructura del negocio y se denominan inversionistas, o aquellos que desarrollan la función productiva y se definen como empleados; los externos pueden ser verticales u horizontales. Los primeros son clasificados como clientes y proveedores y los segundos como competidores y demás organizaciones civiles, estatales, sociales o empresariales que demarcan el entorno empresarial. Si la empresa logra cumplir en estos tres frentes, puede desarrollar ventajas competitivas que la diferencien de la competencia al interior del mercado. El fenómeno que se ha presentado desde finales del siglo xx, y que aborda lo que va del siglo xxI, es el 
incremento de la inversión en términos financieros del presupuesto destinado a desarrollar departamentos de RSE y además, tomar esta disciplina como un argumento de venta.

En ese sentido la visión desde la praxeología sobre la RSE se enfocaría en reconocer inicialmente que toda acción es lógica y racional porque persigue un fin. Sin embargo, la acción se debe regular en términos de los efectos principalmente negativos que se presentan en el acceso al mercado por parte de oferentes y demandantes.

El concepto de mercado también conecta un sentido cooperativo, que provee un espíritu de paz, donde se establece la importancia de cooperar en el mercado, entendido como la multiplicidad de redes de interacción continua y constante sobre la compra y venta de productos a partir de los malestares de carácter individual. De esto se desprende que el reconocimiento del otro, de su individualidad, daría pie a que las empresas entiendan que el relacionamiento con los diferentes acreedores y accionistas y el espectro ambiental deben ser particulares o individuales; es decir, las organizaciones deberían estudiar cómo su actividad puede afectar a diferentes acreedores y accionistas, con el fin de establecer acciones de prevención, mitigación, reparación e inclusive de compensación en pro de que no se vean afectadas las condiciones de los actores para acceder al mercado. La externalidad se puede ver como una distorsión de las redes de mercado, y la RSE sería la disciplina encargada de eliminar esa distorsión y asegurar los espacios de cooperación de las organizaciones.

La RSE se ha presentado como una forma en que las empresas se ven obligadas a nivel moral y ético a reducir o mitigar los efectos negativos que puede llegar a tener su actividad económica. Tal posición ha sido aceptada socialmente aunque ha sido blanco de numerosas críticas al interior de los modelos económicos como es el caso del neoliberalismo, en cabeza de Friedman $(1962 ; 1980)$, quien ha dicho que los únicos sujetos de responsabilidad social existentes a nivel económico y político son los individuos, por lo tanto, la única conciencia social que puede llegar a tener la empresa, es a través de la toma de decisiones empresariales que toma el dirigente. Las empresas entonces tienen responsabilidades artificiales, pero no de negocios. Tal premisa confirma las tesis del libertarismo, en las que el beneficio social depende de la relación entre oferta y demanda al interior de un mercado, donde la única función del Estado es la regulación, lo que significa que la RSE no debería ser impuesta por una legislación, sino que debe ser un atributo de importancia y competitividad entre las empresas frente a la toma de decisiones de los consumidores. Esta tesis rompe el 
paradigma de equiparar la RSE a un acto filantrópico o desinteresado de las organizaciones. Por el contrario, esta hace parte de una premisa utilitarista, donde tanto individuos, como agentes económicos buscan maximizar sus utilidades a partir de la relación ingreso/costo.

Desde el punto de vista metodológico, la praxeología asume elementos similares a los definidos por Santo Tomás, pues objeta que toda acción puede ser intuitiva o automática (cumpliendo con las tres condiciones expuestas por Mises), pero también puede ser cautelosa, pensada y reflexionada, a partir de cuatro fases: ver, juzgar, actuar y devolución creativa.

Bajo esta línea de trabajo, la toma de decisiones al interior de las empresas entorno a la RSE partiría de la fase ver, que implica estudiar, analizar y definir cómo la práctica de carácter productivo genera externalidades tanto positivas como negativas, en las que son fundamentales no solo los ejercicios de empatía para entender el impacto sobre diferentes acreedores y accionistas, sino sumar criterios objetivos que contribuyan a visibilizar los componentes de la problemática.

La segunda fase, juzgar, se enfocaría en dar solución a la problemática reconocida e identificada, de allí que se divida desde el punto de vista hermenéutico en cuatro pasos. El primero es problematizar la práctica tratando de definir el efecto que causa a la empresa, no atender la externalidad; el segundo es la formulación de la hipótesis para establecer diferentes soluciones a la externalidad - el discurso implica el desarrollo de textos o conceptos que logren comunicar de forma efectiva la problemática y su solución-; finalmente, la cuarta fase es retornar a la fuente del problema o la relación con los acreedores y accionistas para socializar la solución en pro de concertar — se asume nuevamente el componente de cooperación como un elemento central en el ámbito relacional—, ya sea por medio del mercado para limitar las externalidades negativas asociadas a las actividades de mercado, las competencias de negociación y mediación. Para los perfiles asociados al área de RSE, estas deben ser prioritarias, en tanto se asuma la negociación, con una visión cooperativa, el denominado gana-gana, debido a que la empresa debería estar preocupada no solo por una negociación en el corto plazo, sino relaciones que se entienden en cataxía como programas de intercambio, los cuales asumen diferentes temporalidades.

Actuar se convierte en la tercera fase que no es más que la operativización o la puesta en marcha de las soluciones concertadas en la etapa anterior, para esto la empresa debe 
establecer objetivos (acción + fin), que involucren de lleno los acuerdos como una extensión de la solución a las problemáticas, con esto puede delimitar núcleos de acción, entendidos como campos de atención, los medios o recursos para acompañar el desarrollo estratégico.

Finalmente, la fase devolución creativa, que se enfoca en determinar aquellos aprendizajes a nivel organizacional que se concluyen de todo el proceso. Para el caso de la RSE se podría denominar un repositorio o banco de lecciones aprendidas y buenas prácticas, que se deben convertir en políticas organizacionales con el fin de generar mecanismo de contenido eficaz y eficiente, sobre la prospectiva propia del quehacer productivo de la organización con respecto a su entorno y sus acreedores y accionistas.

\section{Conclusiones}

En este aparte se evidencia que la construcción de conclusiones respecto a esta temática no es tarea sencilla toda vez que se terminará circunscribiendo lo aquí inferido en los términos de la praxeología. En cuanto a la RSE, se observa que se ajusta a las fases establecidas en el enfoque praxeológico que se sitúa en el cruce de la investigación teórica, de la investigación-acción, de la investigación aplicada e implicada y es, además, un método multireferencial y pluridisciplinario.

De otro lado, la RSE se ve como un campo de reflexión racional y argumentada, que se distancia de las prácticas o hábitos que no generan en ningún momento una actividad de reflexión lógica o filosófica frente a lo que realmente puede llegar a ser la RSE.

La RSE es la primera conexión que se presenta en entender que tanto individuos como empresas son actores racionales, que generan conductas intencionales en pro de satisfacer alguna necesidad. Por lo tanto, toda decisión a nivel administrativo, jurídico, legislativo, de consumo o de producción parte de un hecho irrefutable: la conciencia que nos hace responsables de nuestras acciones, dado que generamos un proceso lógico que consiste en la identificación de un malestar por parte del actor, la imaginación asociada a la proyección sin el malestar y finalmente tener fe en que esa acción va a generar un cambio del estado inicial. 
Igualmente, se puede precisar que la visión desde la praxeología sobre la RsE se enfocaría a reconocer inicialmente que toda acción es lógica y racional, porque persigue un fin. Sin embargo, la acción se debe regular en términos de los efectos principalmente negativos, que se presentan en el acceso al mercado por parte de oferentes y demandantes.

Por último, es necesario precisar que la posición socialmente aceptada de la RSE se ha presentado como una forma en que las empresas se ven obligadas a nivel moral y ético a reducir o mitigar los efectos negativos que puede llegar a tener su actividad económica.

\section{Referencias}

Alvarado, A., Bigné, E., \& Currás, R. (2011). Perspectivas teóricas usadas para el estudio de la responsabilidad social empresarial: una clasificación con base en su racionalidad. Estudios Gerenciales, 27(118), 115-138. https://doi.org/10.1016/S0123-5923(11)70149-8

Bourdieu, P. (1972). Esquisse d'une théorie de la pratique. Paris: Universidad de La Sorbona.

Bourdieu, P. (2003a). Capital cultural, escuela y espacio social. Buenos Aires: Prometeo.

Bourdieu, P. (2003b). El oficio de científico. Ciencia de la ciencia y reflexividad. Barcelona: Anagrama.

Calderón, G., Álvarez, C. M., \& Naranjovalencia, J. C. (2011). Papel de gestión humana en el cumplimiento de la responsabilidad social empresarial. Estudios Gerenciales, 27(118), 163-188. https://doi.org/10.1016/S0123-5923(11)70151-6

Caneda, M. C. (2004). La responsabilidad social corporativa interna: la "nueva frontera" de los recursos humanos. Madrid: ESIC.

Castoriadis, C. (2004). Sujeto y verdad en el mundo bistórico-social. Seminarios 1986-1987. La creación humana I. Buenos Aires: Fondo de Cultura Económica.

Deleuze, G. (2002). Empirismo y subjetividad. Barcelona: Gedisa.

Escudero, M., \& García, J. (2014). La responsabilidad social empresarial y la creación de valor en América Latina. Publicaciones de la Universidad de Deusto.

García, T., \& García, A. (Coords.). (2005). La responsabilidad social de las empresas y los nuevos desafíos de la gestión empresarial. Valencia: Publicaciones Universidad de Valencia.

Garfinkel, H. (1991). Respecification: Evidence for locally produce, naturally accountable phenomena of order. Cambridge: Cambridge University Press. 
Guibert, J. M. (Coord.). (2009). Responsabilidad social empresarial: Competividad y casos de buenas prácticas. San Sebastian: Universidad de Deusto.

Herrera, J., Larrán, M., Lechuga, M. P., \& Martínez-Martínez, D. (2014). Evolución de la literatura sobre la responsabilidad social en PYMEs como disciplina científica. Revista Europea de Dirección y Economía, 24(2), 117-128. https://doi.org/10.1016/j.redee.2014.06.001

Jaramillo, L. G. (2003). ¿Qué es epistemología? Cinta de Moebio, (18). Recuperado de http:// www.moebio.uchile.cl/18/jaramillo1.html

Juliao, C. G. (2002). La praxeología: una teoría de la práctica. Bogotá: Corporación Universitaria Minuto de Dios.

Juliao, G. (2011). La responsabilidad social: una practica de vida. Bogotá: Corporación Universitaria Minuto de Dios.

Kanji, G. K., \& Chopra, P. K. Corporate social responsibility in a global economy.

Total quality management \& business excellence, 21(2), 119-143.

Kant, E. (1966). Reflexions sur l'éducation. Paris: Vrin.

López, A., Ojeda, J. F., \& Ríos, M. (2017). La responsabilidad social empresarial desde la percepción del capital humano. Estudio de un caso. Revista de Contabilidad, 20(1), 36-46.

Maslow, A. H. (1943). A theory of human motivation. Psychological Review, 50(4), 370-396. https://doi.org/10.1037/h0054346

von Mises, L. (1949) Human action: A treatise on economics. New Haven: Yale University Press.

Moles, A., \& Rohmer, E. (1977). Théorie des actes. Paris: Casterman.

Peláez-León, J. D., García, M., \& Azuero, A. R. (2011). La relación estratégica entre gestión humana y la responsabilidad social empresarial: Avances de una explicación en un caso colombiano. Suma de Negocios, 5(11), 15-28. https://doi.org/10.1016/S2215-910X(14)70016-3

Pigou, A. C. (1920) The economics of welfare. Londres: Macmillan and Co.

Porter, M. E., \& Kramer, M. R. (2002). The competitive advantage of the corporate philanthropy. The Harvard Business Review, 5-16.

Schön, D. (1998). El profesional reflexivo. Madrid: Paidós.

Saldarriaga, J. G. (2013). Responsabilidad social y gestión del conocimiento como estrategias de gestión humana. Estudios Gerenciales, 29(126), 110-117. https://doi.org/10.1016/ S0123-5923(13)70026-3

Sartre, J. P. (1960). La critique de la raison dialectique. Paris: Gallimard.

de Sebantián, L. (2007). Responsabilidad Social de la Empresa, 146. Madrid: Cáritas Española. 
St-Arnaud, Y. (1992). Connaître par l'action. Montreal: Presses de l'Université de Montreal. Taylor, F. W. (1911). The principles of scientific management. New York: Harper \& Brothers. Turner, R. (1974). Ethnomethodology. Harmondsworth: Penguin Book. 